\title{
Measurement and Evaluation for Prognostics and Health Management (PHM) for Manufacturing Operations - Summary of an Interactive Workshop Highlighting PHM Trends
}

\author{
Brian A. Weiss ${ }^{1}$ and Michael P. Brundage ${ }^{2}$ \\ ${ }^{1,2}$ National Institute of Standards and Technology, Gaithersburg, Maryland, 20899, USA \\ brian.weiss@nist.gov \\ michael.brundage@nist.gov
}

\begin{abstract}
Personnel from the National Institute of Standards and Technology (NIST) organized and led a Measurement and Evaluation for Prognostics and Health Management for Manufacturing Operations (ME4PHM) workshop at the 2019 Annual Conference of the Prognostics and Health Management Society held on September $23^{\text {rd }}, 2019$ in Scottsdale, Arizona. This event featured panel presentations and discussions from industry, government, and academic participants who are focused in advancing monitoring, diagnostic, and prognostic (collectively known as prognostic and health management (PHM)) capabilities within manufacturing operations. The participants represented a diverse cross-section of technology developers, integrators, end-users/manufacturers (from small to large), and researchers. These contributors discussed 1) what works well, 2) common challenges that need to be addressed, 3 ) where the community's priorities should be focused, and 4) how PHM technological adoption can be sped in a costeffective manner. This report summarizes the workshop and offers lessons learned regarding the current state of PHM. Based upon the discussions, recommended next steps to advance this technological domain are also presented.
\end{abstract}

\section{KEYWORDS}

Diagnostics, Maintenance, Manufacturing, Measurement, Monitoring, Prognostics, Standards

\section{INTRODUCTION}

Prognostics and Health Management (PHM) is an approach focused on advancing monitoring, diagnostic, and prognostic capabilities for a product or process so corresponding

Weiss et al. This is an open-access article distributed under the terms of the Creative Commons Attribution 3.0 United States License, which permits unrestricted use, distribution, and reproduction in any medium, provided the original author and source are credited.

https://doi.org/10.36001/IJPHM.2021.v12i1.2653 maintenance strategies become more proactive and less reactive (Kalgren, Byington, Roemer, \& Watson, 2007). The concept of increasing the efficiency of maintenance operations is not new; industry has recognized enhanced maintenance capabilities as a way to become more competitive given maintenance's impact on cost, quality, productivity and overall customer satisfaction (Luxhoj, Riis, \& Thorsteinsson, 1997). PHM has a strong history of application in both the automotive and aerospace industries (S. Holland, 2020; S. W. Holland, Barajas, Salman, \& Zhang, 2010; Roemer, Nwadiogbu, \& Bloor, 2001). More specifically, PHM technologies are used to monitor and predict the health of the overall product (e.g., automobile, aircraft) and key constituent components (e.g., engines) to optimize maintenance activities.

Another industry that benefits from the advancement and implementation of PHM is manufacturing, particularly in the operations and processes that serve to produce parts and provide desired services (Barajas \& Srinivasa, 2008; Ly, Tom, Byington, Patrick, \& Vachtsevanos, 2009). The successful adoption of PHM promotes increased profit and decreased cost through the reduction of equipment downtime and preservation of necessary part quality and productivity to meet consumer demand (Thomas, 2018). PHM is being applied within the manufacturing industry with pockets of success (Jin, Siegel, et al., 2016). The successful application of PHM requires the technology go through appropriate verification and validation $(\mathrm{V} \& \mathrm{~V})$. Manufacturers have typically developed their own specific test methods for $\mathrm{V} \& \mathrm{~V}$ of newly adopted PHM practices (Jin, Weiss, Siegel, \& Lee, 2016). Likewise, the manufacturing community has found value in applying standards and guidelines developed under the management of standards development organizations (International Organization for Standardization, 2009, 2012). Individually-developed testing practices are usually tailored to a specific technology or implementation; they are seldom reusable for other implementations. Similarly, many of the manufacturing-focused standards currently available are 
focused on specific technological implementations and do not cover the entire spectrum of PHM capabilities that are emerging or currently in use (Vogl, Weiss, \& Donmez, 2014). There is a gap to be filled in developing relevant products to promote the manufacturing community's ability to design, implement, verify, and validate critical PHM capabilities.

Personnel at the National Institute of Standards and Technology (NIST) are conducting numerous research efforts to fill this gap. Beginning in 2013, NIST personnel developed a measurement science roadmap based upon industry input to focus on the most critical research topics whose realization could be impactful within the manufacturing community (Pellegrino, Justiniano, Raghunathan, \& Weiss, 2016). NIST manufacturing PHM research activities in machine tools (Vogl, Calamari, Ye, \& Donmez, 2016), robotics (Qiao \& Weiss, 2017; Brian A Weiss \& Klinger, 2017), and natural language processing (M. E. Sharp, Sexton, \& Brundage, 2016) have paralleled community outreach efforts to ensure the research continues to address the most critical challenges.

This article details the Measurement and Evaluation for Prognostics and Health Management for Manufacturing Operations (ME4PHM) Workshop that was held at the 2019 Annual Conference of the PHM Society on September $23^{\text {rd }}$, 2019 in Scottsdale, Arizona. This event featured panel presentations and discussions from industry, government, and academia who are focused in advancing monitoring, diagnostic, and prognostic (collectively known as PHM) capabilities within manufacturing operations. Documenting this event further builds upon industry's identified PHM needs and challenges, along with sharing some best practices in the design, adoption, verification, and validation of PHM technologies within manufacturing environments.

The remainder of this article is structured as follows. Section 2 offers background on the recent manufacturing evolution and how it has led to increased awareness and buildup of PHM capabilities. Section 3 presents several prior community outreach events since 2013 including a measurement science roadmapping workshop, an industry forum, and a natural language processing workshop. Section 4 discusses the ME4PHM workshop including the four panelist-driven panels ${ }^{1}$ and the final panel on industrial artificial intelligence. Section 5 shares lessons learned and key takeaways from the ME4PHM workshop. Section 6 discusses next steps stemming from the workshop outcomes and concludes the article.

\footnotetext{
${ }^{1}$ The views expressed in the workshop's sessions were those of the panelists and do not necessarily reflect the official policy or position of any agency, organization, employer or company. Each panelist was given approximately
}

\section{BACKGROUND}

\subsection{Manufacturing Evolution}

The manufacturing industry is undergoing an evolution with the rise of Industry 4.0, sometimes referred to as Smart Manufacturing (M. Helu \& Hedberg, 2015; Kagermann, Helbig, Hellinger, \& Wahlster, 2013; Kolberg \& Zuhlke, 2015). The emergence of disruptive technologies (e.g., additive manufacturing, collaborative robotics), increased computing power and data storage, advanced analytics and artificial intelligence (AI), and greater sensing capability in smaller form factors at less cost offer the manufacturing community a myriad of tools with which to enhance their manufacturing operations. Likewise, manufacturers are becoming more motivated to adopt these advanced and emergent technologies as they increase their competitiveness through more frequent equipment and process configurations. Adoption of these technologies allows manufacturers to provide more customized solutions to their customers, as they replace aging equipment and infrastructure, and establish new manufacturing facilities to bring their products closer to their consumers (Bi, Lang, Shen, \& Wang, 2008; Jovane, Koren, \& Boer, 2003). Advancing maintenance practices to become more efficient, less costly, and less time-consuming is part of this manufacturing evolution (Coleman, Damodaran, Chandramouli, \& Deuel, 2017). The application of PHM to the manufacturing domain is aimed at leveraging and advancing monitoring, diagnostic, and prognostic capabilities to optimize planned maintenance and minimize unplanned maintenance.

\subsection{Manufacturing PHM}

PHM is actively being applied in the manufacturing domain and enhancing the competitiveness of many organizations through greater and more stable product quality, productivity, and asset availability. Numerous studies have been conducted to explore the wide range of applicable methods that can be applied across the manufacturing landscape (Peng, Dong, \& Zuo, 2010; Vogl, Weiss, \& Helu, 2019). Advanced monitoring techniques, along with innovative diagnostic and prognostic measures have been applied to machine tools to better plan maintenance of the overall system (Al-Habaibeh \& Gindy, 2000; Mori, Fujishima, Komatsu, Zhao, \& Liu, 2008) along with key components including spindles and trucks (Albertelli, Goletti, \& Monno, 2013; Li et al., 2015; Vogl, Jameson, Archenti, Szipka, \& Donmez, 2019). PHM is also being applied to monitor the health of robots and the larger workcells they comprise (A. S. Klinger \& B. A. Weiss, 2018; Yamada \& Takata, 2002). Crosscutting PHM research is also being performed in such areas of natural language

10 days to review their respective summaries. All panelist comments that responded approved their sections with or without revisions. All requested revisions were incorporated. 
processing and data analysis (Lee, Lapira, Bagheri, \& Kao, 2013; M. Sharp, Brundage, Sprock, \& Weiss, 2019; M. E. Sharp et al., 2016) This research is being conducted across numerous organizations in the academic, government, and industrial sectors.

Personnel at NIST are conducting numerous research efforts to develop publicly-available methods, data sets, and tools to promote the design, deployment, verification, and validation of PHM capabilities for use in manufacturing operations. Research is being conducted in the following PHM-driven areas:

- Degradation Measurement of Robot Arm Accuracy - this research is focused on detecting robot performance degradation by monitoring the accuracy of the robot's tool center position. This research includes the development of a four-level sensing and analysis structure along with the development of a novel six degree-of-freedom (DOF) smart target that is paired with a vision system to acquire fine resolution position information of the robot (Qiao, 2019; Qiao \& Weiss, 2018). Figure 1 highlights the smart target that was developed in the scope of this work.

- Identification and Isolation of Robot Workcell Health Degradation - this effort is developing capabilities to monitor the health degradation of key components operating within a robot workcell that impact quality and productivity. To date, a test method has been developed, and paired with a novel position verification sensor, that will identify sources of degradation within a robot workcell's kinematic chain (A. Klinger \& B. A. Weiss, 2018; Brian A Weiss, 2019)

- $\quad$ Linear Axes Diagnostics and Prognostics - this work is actively developing monitoring, diagnostic, and prognostic capabilities to raise the understanding of machine tool health with a specific emphasis on the stacked linear stages that position parts within a machine tool. Researchers have developed an innovative inertial

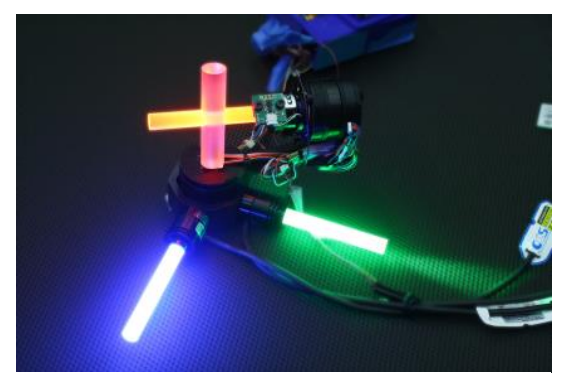

Figure 1. 6DOF Smart Target

measurement unit and coupled this with a test methodology to ascertain straightness, position, and angular errors to the micrometer and micro-radian levels

\footnotetext{
2 https://www.nist.gov/services-resources/software/nestor
}

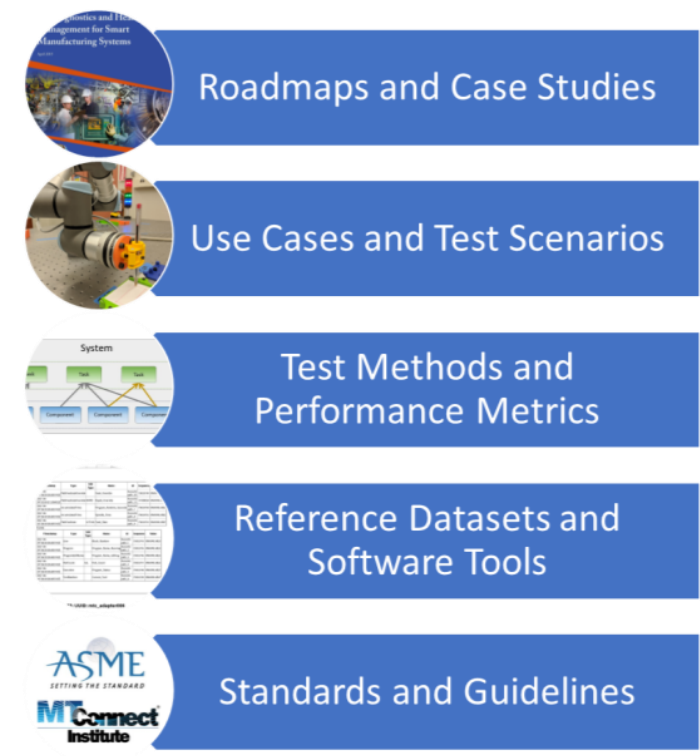

Figure 2. NIST-developed Measurement Science Research Products

(Szipka, Archenti, Vogl, \& Donmez, 2019; Vogl, Galfond, \& Jameson, 2019).

- Knowledge Extraction and Application - this research focuses on developing measurement capabilities and software tools using actionable, computable, domain knowledge from informal text-based data to increase the manufacturers' ability to conduct data-driven and model-based analyses. Specifically, personnel are taking human-generated maintenance work orders (MWOs) and creating tools ${ }^{2}$ to encode the diagnostic processes documented by manufacturing maintenance personnel. This includes making the data computable by translating unstructured text (replete with misspellings, abbreviations, and domain-specific jargon) into a formal schema (T. Sexton, Brundage, Hoffman, \& Morris, 2017; T. Sexton, Hodkiewicz, Brundage, \& Smoker, 2018).

Figure 2 presents the multitude of measurement science research products that these efforts have and continue to output. These research efforts were conceived with feedback from the manufacturing community with input from past events (e.g., workshops, forums) and surveys. These activities have been documented to ensure future events build upon past efforts.

The NIST's measurement science research in manufacturing PHM is very focused on the performance measurement, including verification and validation, of emergent PHM technologies in the manufacturing domain. The broader research community has successfully developed building block efforts, too numerous to detail here. This research includes the development of PHM technology, performance 
measurement techniques, manufacturing capabilities, manufacturing PHM technologies, and performance measurement of manufacturing technologies.

\section{COMmunity OUTREACH}

The driving focus of the ME4PHM Workshop was predicated upon several prior NIST-led events along with key interactions with manufacturers through surveys and other feedback mechanisms.

\subsection{Roadmapping the Priorities and Needs}

NIST personnel hosted a Roadmapping Workshop: Measurement Science for Prognostics and Health Management of Smart Manufacturing Systems in 2014 to identify the priorities and needs of the manufacturing community with respect to their maintenance strategies (Pellegrino et al., 2016; Brian A. Weiss et al., 2015). This event featured over 70 attendees comprising academia, government, and industry along with trade associations and standards development organizations. Many key findings emerged from this event along with 15 specific roadmaps, 8 of which are influencing NIST's research in manufacturing PHM. Some of the key themes that emerged include:

- Identifying advanced sensing capabilities to enhance PHM in manufacturing operations

- Obtaining real failure data to promote the development of prognostics and diagnostics

- Identifying appropriate PHM performance metrics

- Creating an infrastructure to deliver relevant timely intelligence

- Fostering an open-source community for PHM

\subsection{Manufacturing PHM State-of-the-Art}

Multiple organizations collaborated to query the manufacturing community, including small to medium-sized manufacturers (SMMs) regarding the state of the existing maintenance practices and corresponding PHM capabilities (Moneer Helu \& Weiss, 2016; Jin, Siegel, et al., 2016; Jin, Weiss, et al., 2016). This included surveying nearly 40 manufacturers across multiple industries including automotive, aerospace, and consumer electronics. Key findings from this effort include:

- Real data illuminates performance - an organization's perception of how they rate their maintenance activities was determined to be different than the reality when presented with real data.

- Numerous manufacturers, particularly SMMs, want to improve their maintenance activities, yet either are not sure where to start or have other priorities they want/need to address first.
- Manufacturers that have improved their maintenance capabilities typically turn to customized solutions if commercially-available products are too restrictive or expensive

This study proved very insightful. The key findings are further motivation for the development of standards and guidelines to promote the design and adoption of manufacturing PHM technologies.

A more recent study was conducted by NIST personnel in close collaboration representatives from academia and industry (Brundage et al., 2019). This study focused on accounting for human-driven maintenance activities within manufacturing when integrating new technologies. Decisionmakers, including equipment operators and maintenance personnel, are not blending their human knowledge with availability automated and digital capabilities to generate an effective maintenance program that includes appropriate monitoring, diagnostic, and repair efforts. This work laid out existing error mitigation frameworks from human factors experts to promote the implementation of emergent technologies that can enhance maintenance management.

\subsection{Building a Standards Community}

As the priorities and challenges of the manufacturing community were clarified, it became evident that there were gaps in the existing standards landscape, particularly in those standards that focused on advancing monitoring, diagnostic, and prognostic technologies for manufacturing operations. NIST personnel collaborated with the American Society of Mechanical Engineers (ASME) to identify the standards requirements within the manufacturing PHM domain. Numerous topic areas were identified after a workshop in 2017 (Brian A Weiss, Alonzo, \& Weinman, 2017). Ultimately, ASME formed a PHM Standards Subcommittee with the charter - Develop standards and guidelines that advance the design and implementation of monitoring, diagnostic, and prognostic capabilities, along with ways of verifying and validating their performance, to enhance adaptive maintenance and operational control strategies within manufacturing. The formal name of this ASME group is the PHM Subcommittee on Advanced Monitoring, Diagnostics, and Prognostics for Manufacturing Operations. This group meets in person semi-annually and conducts monthly teleconferences as it works towards producing publicly-available documents (Brian A Weiss, Brundage, \& Pellegrino, 2020).

\subsection{Manufacturing PHM Industry Forum}

Members of the manufacturing PHM community reconvened at NIST in Gaithersburg, Maryland, USA in May 2018 to participate in a four-day Industry Forum: Advanced Monitoring, Diagnostics, and Prognostics for Manufacturing Operations that included an ASME standards meeting at its conclusion. The event accomplished its objective "to discuss 
the current trends, successes, challenges, and needs..." so it can advance PHM technologies for enhancing maintenance and control strategies within manufacturing operations (Brian A Weiss, Brundage, Tamm, Makila, \& Pellegrino, 2019). The event included nearly 100 participants with more than 70 individuals representing organizations external to NIST. The Industry Forum featured a combination of keynote presentations and panel discussions across its first three days. The content was broken down into three main topic areas:

- Manufacturing maintenance strategy successes and challenges

- $\quad$ Emerging hardware and software capabilities to enhance equipment and process health intelligence

- Verification and validation techniques to increase confidence in and expand PHM measurements

A significant outcome of this event was a substantial report that detailed the current state of the practice and where the community should focus its energy to further build up PHM capabilities and adoption (Brian A Weiss et al., 2019).

The progress achieved in this event laid the groundwork for the ME4PHM Workshop held over a year after the Industry Forum.

\section{ME4PHM WORKSHOP}

The ME4PHM Workshop was hosted at the 2019 Annual Conference of the PHM Society in Scottsdale, Arizona, on September $23^{\text {rd }}, 2019$. It spanned nearly 8 hours and included 100 attendees. 18 speakers presented their perspectives throughout the day, prompting insightful audience discussion.

\subsection{Overview}

Four workshop goals were articulated to focus the attendees.

- Identify what maintenance practice evaluation techniques work well

- Determine common challenges that need to be addressed

- Identify where the community's priorities should be focused

- Determine what can be done to make technological adoption more cost-effective

These goals were discussed in the context of measurement and evaluation $(M \& E)$ ). If performed correctly, $M \& E$ (which can parallel V\&V) can yield substantial benefits including reducing the risk of technological adoption, promoting direct comparisons of similar implementations, increasing productivity, promoting efficiency, and protecting health and safety.

The overall format of the workshop was structured around four main panel sessions that were preceded by an introductory presentation and concluded by a forwardlooking presentation on artificial intelligence. The four panels were:

- Large Manufacturing - Challenges, Needs, and Best Practices to Verify and Validate PHM Technologies. This panel will be referred to as the Large Manufacturing panel for the remainder of this document.

- Small Manufacturing - Challenges, Needs, and Best Practices to Verify and Validate PHM Technologies. This panel will be referred to as the Small Manufacturing panel for the remainder of this document.

- Technology Development \& Integration - Emergent PHM and the Capabilities that must be Assessed. This panel will be referred to as the Technology Development $\&$ Integration panel for the remainder of this document.

- Measurement and Evaluation Research - Developing Independent Verification and Validation of PHM. This panel will be referred to as the Measurement and Evaluation panel for the remainder of this document.

\subsection{Panel Summaries}

Each panel is summarized including presentation of speaker perspectives along with key questions raised and their corresponding responses. Prior to the first panel focused on large manufacturing, the ME4PHM hosts, Dr. Brian A. Weiss and Dr. Michael P. Brundage, gave an introductory presentation. In addition to discussing the workshop's goals and the benefits of attending the workshop, the overall panel format was presented. For each of the four main panels, each panelist was given a maximum of five minutes to present their background and perspective on manufacturing PHM. After each panelist spoke to the audience, all panelists were invited back to participate in an interactive discussion with the audience. A pre-determined moderator either fielded questions from the audience or asked questions that were known to be of interest to the community. After reviewing the workshop's full agenda, the first panel began. The panels are presented here as a mixture of both panelist's presentations and their subsequent answers during the question and answer period. Figure 3 depicts an image of the workshop venue and its audience during the introductory presentation.

\subsubsection{Large Manufacturing}

The Large Manufacturing panel featured five speakers from a mix of industry and government.

The first speaker was Dr. Sarah Lukens from General Electric (GE) Digital. Dr. Lukens, a data scientist in product development for GE Digital, is focused on asset performance management (APM) and operations performance management (OPM) with the goal of using data to meet business goals. Specifically, Dr. Lukens is concentrating on 
maintenance and reliability where there is substantial opportunity to use data to augment existing work processes. She highlighted several best practice tenants for designing and deploying PHM technologies.

- Meet people where they are today (integrate and augment existing workflows - do not recreate them)

- Template solutions to codify knowledge in algorithms

- Consider analytics the product where analytic techniques are transparent to the user

Dr. Lukens noted that a best practice of her organization is to translate the benefits of their work into dollars (i.e., financial return). This practice makes it easier to obtain customer acceptance and adoption of a specific activity or product. Besides dollars, other metrics that GE measure to gauge the impact of their work include reduction in human capital and reduction in equipment or process downtime.

Dr. Lukens highlighted that it is relatively simple for GE to identify and address specific challenges at a point within a process, yet this becomes more difficult as an organization starts examining these at higher levels across an overall operation. The generation of a risk assessment is part of determining if PHM should be implemented within a machine or process. There is a tradeoff between risk and cost. Dr. Lukens noted that the risk assessment will depend upon multiple factors, which will be dependent upon what an organization wants to accomplish. From her perspective, Dr. Lukens will highlight the opportunities to leverage data analytics.

While analytics offers the prospect of fusing digital data streams, there are numerous elements (e.g., pneumatics, hydraulics) within a manufacturing facility that have yielded analog data, that are captured by skilled operators providing these individuals with very specific domain knowledge. GE recognizes the value of operators' and technicians' domain knowledge and captures it in a meaningful way. They have software that is focused on spot readings, which includes company-generated checklists that operators complete. This includes operators documenting different equipment conditions. The operator-generated data is integrated with other health information, along with maintenance records and

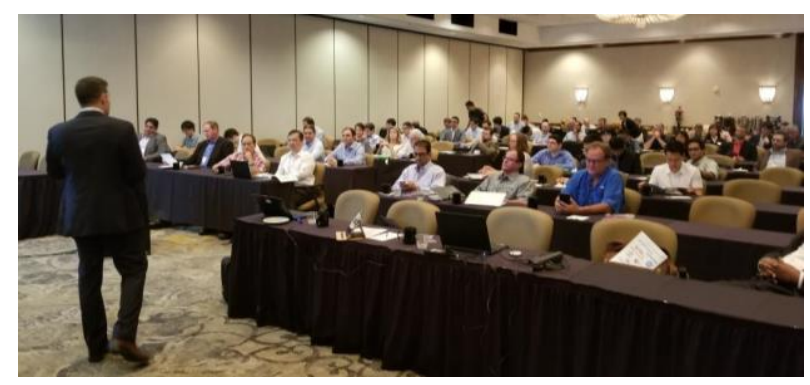

Figure 3. The ME4PHM Workshop during the Introductory Presentation sensor readings, so reliability engineers can ascertain a more complete picture of equipment and process health.

The second speaker of the panel was Mr. Greg Colvin, a Technical Fellow from Honeywell Aerospace. Mr. Colvin highlighted Honeywell as a global conglomerate that has more sensors and connected devices than anyone in the world. One challenge his organization is focused on is targeting the data collection spots that can provide the largest value proposition that minimizes cost and maximizes value. It is important to avoid over collecting and under analyzing data. Another way to increase value is to find the optimal amount of equipment maintenance; avoid too much and too little maintenance. This focus should be balanced with maximizing equipment life and reliability. He noted that Honeywell views inexpensive manufacturing facilities as the future of manufacturing. Honeywell's PHM implementation strategy is integrated with their focus on rolling out a "Smart Factory" to U.S. operations where equipment is connected and monitoring is done in a centralized manner. This effort also includes validating PHM effectiveness and data accuracies while documenting standard practices.

Mr. Colvin notes that some of Honeywell's biggest successes are when they can validate the payback for a PHM verification process. This involves capturing insights from data that enables them to ascertain the value proposition of a specific PHM capability. A challenge that Mr. Colvin cited was assessing an overall manufacturing facility in terms of PHM solution implementation. Sensors can be expensive to procure and integrate. Getting an organization's leadership to support PHM can be challenging. His recommended practice is to start PHM implementations at the lower level(s) of an organization to obtain relatively easy wins. Once lower level value has been demonstrated, then it will become more straight-forward to approach leadership to expand PHM growth.

Additive manufacturing is a disruptive technology that $\mathrm{Mr}$. Colvin highlighted. He indicated that this technology is moving in the direction of adaptive control. Additive manufacturing can be characterized as a very digital process, which could make it ripe for beneficial PHM implementation.

Mr. Colvin's organization is focused in the aerospace industry where parts must be qualified. There are standards in place with respect to qualifying the machines that ultimately produce the parts to be qualified. Machine qualification is expensive. Machine software is typically upgraded multiple times a year, sometimes upwards of 5 to 6 times a year. Every software upgrade must be qualified and becomes costly. Aerospace is one of the more restrictive industries with respect to standards and specifications. Additive manufacturing is a relative green field where manufacturers are still determining how they can effectively and accurately qualify parts. Advancing PHM technologies in the aerospace industry can positively impact part qualification. 
The panel's third speaker was Dr. Chris Yang, the Deputy Director of the Industrial Big Data Office (IBDO) from Foxconn. Dr. Yang noted that Foxconn plays a critical role in the manufacturing of some well-known electronic products including the iPhone, Kindle, Nintendo Switch, Playstation, televisions, and computers. Foxconn is actively transforming its traditional manufacturing processes to integrate many emerging and advanced technologies. These new capabilities include cloud computing, mobile devices, Internet of Things (IoT), big data, AI, smart networks, and advanced robotics and automation technologies. Some of Foxconn's best practices in transforming its manufacturing capabilities are its ability to scale PHM across its enterprise. The organization is currently augmenting over 170,000 computer numerical control (CNC) machine tools with greater PHM to enhance the organization's ability to offer greater information technology (IT) assistance.

Foxconn's strategy for verifying and validating upgrades is still in process. Specifically, they are still connecting devices to obtain data. One methodology they are exploring is creating a data foundry. The perspective is that if you can own the data, then you can use the data to create a more powerful model or software in the future as tools and capabilities become more advanced. Dr. Yang believes you can gain confidence in PHM when these deployments are coupled with AI tools and techniques to provide an asset's health assessment. Another confidence builder in PHM is for engineers to be exposed to this technology, and companion AI tools, sooner in their education and training. This exposure can include company internships.

The next speaker of the panel was Dr. Nicholas Propes, a Senior Staff Data Scientist from Seagate Technologies. Dr. Propes' role is to help internal stakeholders in research and development (R\&D), PHM modeling, machine learning, and simulation. In addressing PHM-related challenges, his organizational priorities are to leverage, measure, and evaluate PHM. Leveraging PHM involves looking at past successes, including internal successes and those cited in external research efforts. Measuring PHM is focused on product and equipment monitoring with sensors. Evaluating PHM is a combination of testing, verification, and validation.

Dr. Propes highlights numerous challenges that heavily influence his active areas of focus. Several of these challenges focus on data; he cites a lack of fault data and validation data sets. Dr. Propes acknowledges that he can collect some data, yet it's unclear if the data is sufficient for training and testing efforts. Labeling data is another noted challenge specifically in that activity could require a substantial amount of effort. Another data challenge is the definition of anomalies since they are frequently not well defined within the data. Given these challenges, Dr. Propes' efforts include a focus on working with simulated data.

While data-driven models have been successful, Dr. Propes notes some accomplishments for him have come in the form of convincing his leadership of the value of physics-based approaches and models. This includes one of his best practices of generating other types of approaches to train models on data.

Dr. Propes talked about how his organization gains confidence to deploy their PHM technology in operational settings. Specifically, there is a need to analyze test data to ensure there is sufficient redundancy and that it does not corrupt any measurements. One of his efforts is devising efficient training and test sets. This is not an easy task and needs to be defined first to ultimately attain deployment confidence.

The final speaker of the panel was Dr. Maria Seale, a Research Computer Scientist from the Information Technology Laboratory (ITL), part of the United States (U.S.) Army Engineer Research and Development Center (ERDC). Dr. Seale is involved in three PHM-related efforts including 1) the Department of Defense (DoD) Joint AI Center Predictive Maintenance (JAIC PMx), 2) Engineered Resilient Systems, and 3) ITL High Performance Data Analytics. ERDC's overall organizational priorities include:

- $\quad$ Providing high performance computing capabilities and data science expertise for analyzing large-scale PHM data

- Collaborating with other DoD organizations to determine high-impact analytics to advise decisions

- Using existing PHM data to guide future designs

Dr. Seale noted the significant PHM big data problem that exists; DoD systems generate large volumes of data during operations making it impossible to completely analyze all of it using common computing methods and resources. ITL's goal is to promote the analysis of terabyte and larger data sets to enhance fleet-wide analytics and decisions. In achieving this goal, ITL is actively addressing several challenges including developing new infrastructure and policies to handle large quantities of data for storage, handling, and analysis. Another ongoing challenge relates to data interoperability - uniformly processing data comprised of data in differing formats.

Dr. Seale's biggest triumph came when her team produced analytics over large data sets that her internal stakeholders could leverage. Her key metrics to measure these big 'wins' are improving the soldier safety along with the reliability, availability, and maintainability of their equipment fleet.

Dr. Seale provided her organization's perspective of V\&V of technology upgrades. She noted that this V\&V of models is an ongoing process and area of research for her. Changing data and model drift are a continuous challenge for her organization. This includes elements changing over time (due to changing data and model drift) yet still within acceptable limits. V\&V of models is a critical activity for those models 
deployed on critical platforms. Given her stakeholders are the DoD community, safety is paramount. Numerous personnel are involved in V\&V including customers, end-users, and field-based subject matter experts.

Overall, the speakers within the Large Manufacturing panel provided a diversity of expertise and responses to the audience questions given their specific research focus areas and organizational missions. This mix of private industry and government perspective highlighted some consistent themes.

- PHM adoption is becoming more of a necessity for organizations to increase their capabilities and competitiveness

- $\quad$ PHM can be applied across a range of technologies from traditional manufacturing operations to emergent manufacturing capabilities (e.g., additive manufacturing)

- $\quad \mathrm{V} \& \mathrm{~V}$ is a non-trivial research area, particularly in the assessment of updates to the field

The following panel focused on the small manufacturing community including some unique challenges they face as compared to their larger counterparts.

\subsubsection{Small Manufacturing}

The small manufacturing panel included four speakers from a mix of industry and academia.

This panel began with a presentation from Dr. Radu Pavel, Vice President and Chief Technology Officer from TechSolve. Dr. Pavel's presentation focused on the challenges, needs, and best practices as they relate to small manufacturing PHM. TechSolve is a private organization that provides manufacturing process solutions, IoT services and products, and business advisory to their local manufacturing community. In addition to working with large original equipment manufacturers (OEMs) in aerospace and defense, they also work with small and medium size manufacturers (SMMs). Part of TechSolve's interaction with the manufacturing community is through the Manufacturing Extension Partnership (MEP); TechSolve is a State (Ohio) and Federal MEP center.

TechSolve has traditionally conducted research and provided consulting focused on machining and grinding processes; they have a fully instrumented machining lab to support these activities. This lab includes various $\mathrm{CNC}$ machine tools instrumented with sensors and data acquisition systems for machine and process condition assessment, and spindle and feed axis test beds for run-to-failure tests. Dr. Pavel believes equipment health and maintenance are vital elements to smart machine tools. It was noted that TechSolve continuously seeks to identify, evaluate, develop and disseminate technologies to manufacturers. This effort is supported by their multiple PHM testbeds that enable a combination of destructive and non-destructive testing.

One of TechSolve's best practices is its use of test beds to evaluate technology. Dr. Pavel noted that SMMs are often skeptical of new technology making it critical to verify that the technology does what it is stated to do as well as understand what efforts and resources are necessary to get the technology to perform as intended. In addition to TechSolve's technology evaluation capabilities, they also participate in technology development at various levels of Technology Readiness Levels (TRLs). Based upon TechSolve's focus on building up the manufacturing capabilities of SMMs, Dr. Pavel noted that it's crucial to create awareness of emerging technologies with the SMM community. Part of creating awareness is generating key informational materials and standards which would include guidelines for best practices. This content should clearly articulate its value to an SMM.

Dr. Pavel also shared that some SMMs don't find it necessary to have every single piece of technology be evaluated. In lieu of an evaluation, some SMMs will go by "word of mouth," based upon positive experiences of others. The SMMs will want to understand the expected return on their investment, as well as information regarding training, maintenance, integration and availability of customer support. Not every SMM requires state of the art technology to enhance their operations. One challenge that some SMMs face when they implement a new technology is that they must dedicate a resource(s) to that technology, which can be particularly difficult with very small companies.

TechSolve does not tie itself to any one specific manufacturing solution. They take care to focus on their customer to ascertain what they want and develop an appropriate business case and targeted solution to ensure a reasonable return on investment for both the customer and TechSolve.

The second speaker of the panel was Ms. Sara Fuller, a project engineer from Mississippi State University's Center for Advanced Vehicular Systems (CAVS) Extension. Ms. Fuller is working with manufacturers to help them overcome the challenges of implementing PHM in their manufacturing processes. She interacts with both SMMs and large companies. CAVS Extension has the resources to support assessments and can also connect SMMs with other organizations (e.g., integrators) that can implement technologies. One of her focus areas is helping manufacturers become more aware of PHM and guiding them to take advantage of PHM's benefits. This includes supporting PHM pilot implementation activities.

One substantial challenge that Ms. Fuller helps SMMs solve is in data analysis. SMMs seldom have data scientists on staff. CAVS Extension supports the SMMs in addressing data issues such as storage, privacy, security, and scalability. 
Ms. Fuller highlighted that a significant success for CAVS Extension is using test beds to test new solutions before they are implemented in operational environments. Collaborating organizations become more enthusiastic in both the process and solution as they see the technology operating within specification on a test bed. This brings the solution closer to the reality of being implemented on their factory floor making it easier for more personnel to 'buy-in.'

CAVS Extension has a role in the state of Mississippi to promote manufacturing in the SMM community; they are part of the Mississippi MEP network. Ms. Fuller noted that to get SMMs involved, it is important to start with the state MEP centers. Each state's MEP center should already have insight into their constituent SMMs. Successfully engaging SMMs requires a mutual level of trust. MEP centers should already have relationships with their SMM constituency, so working through MEP centers builds upon established relationships.

CAVS Extension is careful to tailor its solutions to their customer and the specific problem in focus. Much of the equipment that the SMMs are seeking to augment with PHM is legacy equipment. Before a PHM solution can be appropriately designed and implemented, the baseline performance of the equipment must be characterized. With legacy equipment, no two similar equipment models will perform the same or be in the same condition. This means that a solution that works for one piece of equipment may not work for similar equipment. Solutions can vary between retrofits for legacy equipment to new construction from the ground up. Likewise, Ms. Fuller noted that the operating environment must be factored.

The next speaker of the panel was Mr. Brad Smith, Director of Facilities and Equipment at Ludowici. Ludowici has been in business since 1902 as a roofing and floor tile manufacturer. The company can produce over 1300 different patterns of tile with unlimited colors. This variety produces challenges in production in terms of trying to improve the plant's reliability and productivity. Mr. Smith noted he is responsible for maintaining Ludowici's 250,000 square foot manufacturing facility including implementing capital improvements, ensuring the plant is environmentallyresponsible, maintaining equipment and tooling, and designing and building custom tools. Ludowici designs and builds most of their manufacturing equipment since roofing equipment is not well supported in the U.S.

Mr. Smith noted that much of their maintenance is timebased. This is an area that Ludowici is trying to improve. To support the improvement of their maintenance activities, Ludowici has installed over 70 cameras throughout their facility to help understand faults and failures, if or when they occur.

Mr. Smith noted it is difficult for Ludowici to score big wins in maintenance based upon their limited resources. He noted that help is needed from state MEP Centers and their sub- recipients (e.g., TechSolve, CAVS Extension) to costeffectively advance their maintenance programs. Likewise, consultants are capable of offering beneficial services, yet consultants are likely to cost more than MEP resources since MEP centers are federally funded to build up SMM manufacturing operations.

The last speaker of the panel was Mr. Luis Gonzalez-Mendez, Executive Director of Process Engineering at Trividia Health. Trividia Health is a medical device and product manufacturer. Mr. Gonzalez-Mendez has been integrating PHM in product design where Trividia Health is now at the stage of using PHM. He has been encouraging his design engineers to consider PHM in their corresponding design activities.

Mr. Gonzalez-Mendez noted several challenges with PHM including its occasional high cost and incompatibility of the data and software to manage the data. Given their focus in medical devices and products, Trividia Health conforms to Food and Drug Administration (FDA) guidelines. It was noted that the FDA is becoming stricter on their regulations of medical devices including auditing of specific software tools.

As a SMM, Mr. Gonzalez-Mendez noted that PHM adoption can be a challenge for organizations such as Trividia Health, particularly because PHM is seen as a long-term investment. Regarding their manufacturing process PHM, Trividia Health's maintenance strategies are evolving from preventive to more predictive maintenance, particularly condition-based maintenance. He sees product quality, process reliability and effective equipment maintenance as the most important priorities to leverage PHM. Mr. Gonzalez-Mendez notes that there are ways of saving expenses by increasing PHM capabilities, including reducing the number of spare parts in inventory for manufacturing equipment by understanding what parts are needed and when; and reducing overtime and scrap.

Similar to other presenters, Mr. Gonzalez-Mendez noted that some of Trividia Health's biggest wins are when they can demonstrate a successful PHM implementation where personnel can articulate why degradations are occurring. This translates into showing the benefits to the business.

Mr. Gonzalez-Mendez echoed similar thoughts (relative to other panelists) about SMMs being hesitant to share their data. It was noted that these concerns need to be balanced with what other organizations in their supply chain need to know about their operations to effectively interact with one another. Trust must be built to gain access to an SMM's data or simply form a relationship. When interacting with a SMM for the first time, it is important to have references from other SMMs. SMM communities are typically tight-knit families. For those organizations that have unsuccessful SMMs interactions, it is usually due to the organization not fully understanding the challenges and needs of the particular 
SMM. Likewise, if a company presents the SMM with an unexpected or costly change order, then the relationship is likely to be impacted. Taking great care of SMM relationships can yield long-term benefits.

Cybersecurity is an important element to be addressed in the medical device industry. Mr. Gonzalez-Mendez noted that it is critical to understand how cybersecurity protections impact production. Likewise, it is important to understand the potential impacts when a system is compromised. Small companies face additional costs to ensure their systems are secure and even greater costs in the event of an intrusion. Mr. Gonzalez-Mendez highlighted the need to keep cybersecurity roadmaps simple for the SMM community.

Several key themes emerged in the course of the small manufacturing panel.

- Relationship-building is critical to successfully interacting with the SMM community

- SMM-generated datasets are under-utilized either because SMMs lack the resources to analyze the data or they are wary of sharing their data with potential external collaborators

- $\quad \mathrm{V} \& \mathrm{~V}$ is both critical to demonstrate the capability of a technology and to build confidence in an operational deployment.

The following panel on Technology Development and Integration features participants who are crafting PHM technologies, both hardware and software, to enhance manufacturers' PHM capabilities.

\subsubsection{Technology Development and Integration}

The Technology Development and Integration panel featured five speakers collectively representing industry, academia, and government.

The first speaker of this panel was Dr. David Siegel, Chief Technology Officer of Predictronics Corporation. Predictronics develops and implements PHM solutions for the manufacturing community by leveraging their expertise in various technologies including industrial internet of things (IIoT), industrial AI, big data, machine learning, and predictive analytics. They offer PHM services in the areas of data acquisition and automation services, health monitoring, fault diagnosis, and lifetime prediction. Predictronics works in a range of manufacturing industries, yet a majority of Predictronics' business is in the area of discrete manufacturing.

Dr. Siegel noted that when they begin a project with a customer, the first action is to ensure they have support from the top of the management chain. This is also an opportunity to clearly ascertain the organization's goals in a PHM investigation and implementation along with the specific data the organization would like to capture. Once management approval is obtained, the next step is to determine what data and information is available. Most collaborations include pilot activities, which typically range from three to six months in duration.

One of the areas that Predictronics has successfully implemented PHM functionality is with respect to industrial robot arms. Dr. Siegel highlighted a predictive monitoring effort that was conducted with 6DOF arms and demonstrated that the fifth axis of an arm had degraded. Given the degradation was not at the point where it was impacting production, the arm was repaired on a weekend resulting in no loss of productivity since production was not scheduled over weekends at this organization.

Dr. Siegel highlighted that discrete manufacturing is relatively data poor, yet rich in challenges and problems. PHM effectiveness is hard to show unless machines are progressing towards failure. PHM solutions are not developed in isolation. One element that enhances PHM effectiveness is data. The PHM community craves real data, particularly those sets that capture faults and failures. Real fault and failure datasets are difficult to acquire.

As a PHM solutions provider, Dr. Siegel noted that it is important to understand how specific technologies provide value and enhance a business case. He mentioned two specific technologies, analytics and machine learning, as being critical to PHM, yet still evolving. Dr. Siegel notes that success is not necessarily tied to the latest and greatest technologies or algorithms. Methodologies and approaches are also important. One area worthy of further investigation is that of explainable AI. Understanding explainable AI would indicate what variables are contributing to an output decision based upon a given dataset. Explainable AI offers transparency to highlight how decisions are made.

Predictronics' project's piloting activities typically begin with a subset of the number of machines (3-5 typically considered in a pilot) in the factory. The organization will employ analytics with anomaly detection to generate initial success. Their next steps are usually to add diagnosis and prognosis capabilities. These activities are first supported by a few sensors and more sensors are added as the pilot progresses.

The second speaker of the panel was Mr. Mark Walker, Chief Technologist from D2K Technologies. Mr. Walker highlights D2K Technologies as an AI software solutions company and describes himself as a PHM practitioner. D2K focuses on holistic solution development. This includes performing a requirements derivation that aims to determine an appropriate solution for the customer. Requirements derivation is part of the engineering services and solutions development D2K provides.

Mr. Walker has first-hand experience conducting abnormal situation management and anomaly detection. He has delivered practical solutions that have a positive impact on 
his customers; D2K develops their own platform/PHM capability to produce a working, maintainable, and verifiable solution that can be used by their customers. Mr. Walker aims to make this platform extendable where the customer's mission (e.g., operational objective) can be mapped to the software. One key goal of this approach is to understand how the results can be made useful to decision support; D2K is doing this exact activity with NASA, their largest customer.

Mr. Walker noted that the concept of the digital thread and the use of an underlying model for both the process and the enterprise is a welcome development that helps in verification and performance measurement. Two of D2K's performance measures are 1) value to and 2) satisfaction of the customer. Performance is heavily influenced by the available data that is analyzed. Mr. Walker notes that several challenges present themselves with real world data as compared to what is experienced in a more controlled lab setting. The first challenge to overcome is creating software models that map well to what stakeholders are seeking. The second challenge is working within agile development processes and software quality assurances. Mr. Walker mitigates these challenges with frequent check-ins with his customers to promote transparency when modifications or refinements need to be made.

Mr. Walker believes that their current and prospective large manufacturing customers are shifting toward the PHM technological domain. He has not had to come up with innovative ways to raise the awareness of PHM. This is one piece of evidence to support his belief that the marketplace is ripe for PHM adoption and it is time to be more proactive in raising awareness of PHM. As more organizations gravitate towards PHM, he is positioning D2K to be part of the technological development process when a larger wave of PHM adoption occurs.

The next speaker was Mr. Ed Spence, Founder and Managing Director at The Machine Instrumentation Group. Mr. Spence represents a collaborative network of engineering services, with expertise in Condition Based Maintenance (CBM) and PHM instrumentation. His focus is to enable CBM/PHM programs for machine makers / OEMs. Mr. Spence noted that the application of CBM and PHM can be further expanded by the OEMs into the Green Field where operations are deemed critical or downtime can be expensive. Mr. Spence's believes there is large room for CBM industry expansion with embedded sensor instrumentation within OEM systems, focusing on enabling the development of CBM programs by the machine makers themselves.

Mr. Spence noted multiple competencies are required to develop and implement effective PHM solutions. These competencies include 1) OEM and SMM engagement, 2) data acquisition, 3) health indicator development with advance analytics, 4) sensor development, and 5) condition monitoring instrumentation. Mr. Spence highlighted numerous obstacles with PHM. Some of these challenges include having a sufficient library of faults and failures along with appropriate test data, shortage of relevant competencies such as data engineering. The emergence of IoT technologies presents its own set of challenges for SMMs. Given his experience working with small companies, Mr. Spence builds a customer's confidence in PHM by outfitting an existing machine with additional sensing capabilities to obtain new data.

The fourth speaker was Mr. Frank Zahiri, Technology Insertion Manager with U.S. Air Force Sustainment Center at Warner Robins Air Force Base (AFB). Mr. Zahiri introduced the concept of health monitoring at Warner Robins AFB and introduced PHM-enabling instrumentation for critical machines on the base. Mr. Zahiri was tasked to turn Warner Robins' manufacturing operations into a digital factory that leverages emerging manufacturing technologies. To address this goal, he developed an architecture derived from existing efforts conducted by Georgia Tech, NIST, and the National Science Foundation (NSF). The architecture includes elements of smart manufacturing, IIoT analytics, digital twin, digital manufacturing, and a corresponding IIoT platform. Mr. Zahiri noted that smart manufacturing includes operations and maintenance, production planning and scheduling, process monitoring and control, and factory analytics. Specific to the Air Force, Mr. Zahiri noted that Warner Robins is investing in numerous technological areas including instrumentation, smart data mining technologies, fault diagnosis, prognosis, model-based systems engineering, and predictive maintenance.

As a member of the DoD and someone who is heavily involved with the Air Force's Small Business Innovation Research (SBIR) program, Mr. Zahiri indicated his organization should be at the leading edge of technologies and sensors, including AI-related technologies. Warner Robins currently has multiple projects that are aimed at helping external developers produce new sensors, including sensors to be used on aircraft. In parallel with their sensorfocused hardware efforts, Mr. Zahiri indicated that data is also an area of focus including determining what information should be captured, monitored, and controlled.

Mr. Zahiri has seen some new trends in PHM including capturing more data from legacy machines than previously expected due to the inclusion of new sensors. From his vantage point, he believes OEMs are better recognizing the needs and wants of the end-user community where end-users can better see how data is collected from their equipment to their benefit.

Warner Robins is identifying use cases where AI can be applied to the operational elements of their activities. One such use case under consideration is planned aircraft maintenance. Prior to an aircraft arriving at Warner Robins AFB, a maintenance plan is developed. However, aircraft sometimes arrive in a condition different than expected. Personnel must now re-plan their maintenance activities. Mr. 
Zahiri noted that AI can bring optimized balance to both the revised planning process and the overall maintenance plan. To support their maintenance optimization activities, the Air Force has partnered with an external organization to perform a digital Failure Modes and Effects Analysis (FMEA). The intent is to 'digitize' some of their manufacturing machines so they can 'play back' or 'play forward' machine health. This effort will also support logistics by helping predict when spare parts would be needed so they could be ordered at appropriate time horizons.

The final speaker of the panel was Dr. Sankaran Mahadevan, Professor of Civil and Environmental Engineering at Vanderbilt University. Dr. Mahadevan's research is focused in numerous areas including full-scale structural health monitoring and systems health monitoring, $\mathrm{V} \& \mathrm{~V}$, and digital twin within process monitoring and predictive control. Overall, his main thrust at Vanderbilt is uncertainty management, quantification, and reduction. Another area where he is applying PHM is in the realm of Additive Manufacturing (AM). Dr. Mahadevan noted that models are more complicated in AM. Models need to be verified with online and offline measurements. The most important aspect is minimizing the variability of the product. Dr. Mahadevan has done this minimization with both metallic and nonmetallic parts.

Dr. Mahadevan highlighted several technological innovations that further promote PHM. Specifically, new development in the areas of sensing, modeling, and analytics are enabling the generation of more effective control algorithms. He believes that sensor reliability is an area where more research needs to be conducted and that resource management is critical for effective PHM, including not just sensors, but also algorithms and computing.

Dr. Mahadevan has witnessed a recent leap forward in data analytics methods, partly due to the evolution of sensing and computing. Increased quantities and capabilities of sensors has led to the availability of more data. Likewise, greater computing power has enabled new analytical methods to be employed. More data and corresponding analytics have also led to a renewed focus on uncertainty.

To advance the state of the technology, Dr. Mahadevan recommended bringing in industry partners to support testing activities. Specifically, enlist these partners to determine how well the technologies perform, particularly in operational scenarios (as compared to laboratory environments).

Several key points emerged throughout the presentations and discussion within the Technology Development and Integration panel.

- Many technology developers and solutions providers are increasing their application of AI to promote PHM growth throughout the manufacturing industry
- Advances in sensors and analytics are promoting greater PHM capability and adoption

- Although laboratory experimentation can show promising results, there is no substitute for operational pilots to see how a technology performs in its target environment.

The next panel of the day featured four participants from the U.S. Government who are focused on measuring the capabilities of PHM technologies developed and implemented for use in manufacturing operations.

\subsubsection{Measurement and Evaluation Research}

The Measurement and Evaluation Research panel included four speakers from the U.S. Department of Commerce's National Institute of Standards and Technology (NIST).

This panel began with a presentation from Dr. Brian A. Weiss, Leader of the Prognostics and Health Management for Reliable Operations in Smart Manufacturing project at NIST. Dr. Weiss highlighted his research objective to develop and deploy PHM-focused measurement science to increase reliability and decrease downtime in smart manufacturing systems. NIST defines measurement science as publicly available products that include roadmaps, case studies, use cases, test methods, performance metrics, reference data sets, software tools, and guidelines. Succinctly stated, the effort's output products should enhance the manufacturing community's ability to minimize unplanned downtime and optimized planned downtime.

Dr. Weiss' project conducts research in the domains of machine tools and industrial robotics. Three of the research thrusts in this project were discussed during this panel and are highlighted in Section 2.2-Degradation Measurement of Robot Arm Accuracy, Identification and Isolation of Robot Workcell Health Degradation, and Linear Axes Diagnostics and Prognostics. Dr. Weiss also presented on an emerging research effort focused in spindle health monitoring.

Dr. Weiss noted that NIST researchers are always seeking mutually beneficial collaborations with organizations in the manufacturing community. NIST benefits in that these collaborations are often a means to tune test methods and protocols prior to finalization. External collaborators benefit in that they get an early, first-hand look at governmentdeveloped capabilities that are more likely going to address some of their specific needs and challenges. Dr. Weiss views collaborations as opportunities to obtain data sets from real manufacturing environments. These environments are more prone to faults and failures; similar faults and failures are less likely to be observed in a lab setting.

NIST identifies its specific research goals based upon higherlevel strategy developed by senior leadership. Individual research efforts are framed to provide benefit to a reasonably focused audience as opposed to generating products that are 
specific solutions helping a handful of stakeholders. For example, in developing a capability within industrial robotics, products should be vendor neutral or device agnostic to maximize the user community.

The next speaker of the panel was Dr. Michael P. Brundage, Leader of the Knowledge Extraction and Application for Manufacturing Operations project at NIST. Dr. Brundage's presentation focused on his research effort - Knowledge Extraction and Application - described in Section 2.2. During his presentation, Dr. Brundage elucidated on the research challenges in validating maintenance work order data in the areas of collection, cleaning, and analysis of data. The data collection challenges include misspellings and abbreviations of words, incomplete sentences, inconsistent formats, missing timestamps, and incorrect timestamps. Some of the data cleaning challenges include different classifications, a lack of training or prediction validation, and determining if the classification codes are correct. Lastly, the data analysis challenges centered around knowing if the analysis is measured and reported correctly. Addressing the lack of open data in this field will promote overcoming these challenges.

Similar to Dr. Weiss, Dr. Brundage noted he continually seeks out collaborations with the manufacturing community, both from industry and academia. The greatest mutual benefit that he and his collaborators achieve is sharing data. Ultimately, Dr. Brundage's work falls into the public domain so the overall manufacturing community stands to gain data, and a better understanding of it.

In addition to increasing publicly available data or corresponding analyses of data sets, Dr. Brundage is also a champion of open tools. Dr. Brundage's research effort at NIST has led to the generation of open source tools including the Nestor Graphical User Interface that helps maintenance personnel annotate their MWO data through a process known as 'tagging' (T. B. Sexton \& Brundage, 2019).

Human factors have had a significant impact on the quality of data that Dr. Brundage routinely examines. Maintenance technicians' primary function is to diagnose and repair equipment, not write good data in the form of MWOs.

The third speaker of the panel was Dr. Michael Sharp, an industrial engineer, also from NIST. Dr. Sharp's talk focused on PHM with AI where AI-related tools augment PHM activities. Dr. Sharp noted numerous issues with the underlying AI models including how trust [in the models] can be developed. It was highlighted that when PHM with AI has been used, the results are promising. However, there is still much work to be done within the community. Numerous researchers are undertaking efforts focused on PHM with AI yet there needs to be better communication among these entities to speed both the development and measurement processes.
A key element of improving the development and measurement of AI-based technologies is education. A wide disparity exists in the manufacturing community about the state, capabilities, and ease of integration of AI. When incorrectly applied, it can be relatively easy to mislead people about AI. Some practitioners have used bad datasets, have overfit available data, or made spurious correlations. Ultimately, AI is useful, but it is critical that "good" AI models be recognized from "bad" models.

Dr. Sharp highlighted that collaboration with the manufacturing community is imperative to advance the state of PHM with AI to support manufacturing operations. Manufacturers would stand to gain from measurementfocused collaborations including better understanding of the potential return on investment (ROI) of models and standard set(s) of tools to V\&V standard models.

The final speaker of the panel was Economist Doug Thomas from NIST. Mr. Thomas presented a recent study he had conducted in understanding the costs and benefits of maintenance strategies applied to manufacturing machinery. This effort has led him to understand and further develop the business case for an organization to adopt advanced maintenance practices. At the time of this workshop, Mr. Thomas was analyzing over 70 responses he received to a survey he developed and distributed to the manufacturing community to obtain specific feedback on existing maintenance practices and corresponding expenditures (since the conclusion of the workshop, the results of this survey activity have been published (Thomas \& Weiss, 2020)). Mr. Thomas is taking the key findings of the survey and incorporating them into a software tool that will estimate expected maintenance costs based upon peer values. The hope is that raising awareness of the costs of maintenance in manufacturing (e.g., range of costs, downtime lost by not adopting PHM) will further promote a wave of PHM adoption.

Mr. Thomas is collecting and understanding cost estimation with the intent to anonymously share this with the greater manufacturing community. The goal is to use the anonymous cost data as a motivator to get more manufacturers to share their own cost information to enhance the accuracy and broaden the applicability of Mr. Thomas' work. Mr. Thomas is also using this cost information to develop and document methods for calculating ROI. This product will also be made publicly available once it has been completed.

From Mr. Thomas' perspective, one of the most interesting challenges that he sees manufacturers facing with respect to advancing their maintenance strategies is with their culture. Numerous manufacturers have noted that the way a new technology or capability is introduced can have a significant impact on its adoption and acceptance by the entire organization. Another challenge that manufacturers face is appropriately and correctly measuring the severity and frequency of problems. Data is critical to understanding the 
significance of an issue. Ultimately, this data will help guide an organization in determining what problems should be addressed to maximize their overall ROI.

Mr. Thomas shared his insight on a plausible incentive structure for an organization to implement PHM. He noted that effective PHM can lower the cost per unit manufactured. If all other things remain the same, then profits and/or income should increase. If a company becomes more profitable, then it should be capable of being more competitive, particularly if they need to lower prices as other organizations become more competitive. Likewise, jobs should become more secure within that organization since the company is more likely to thrive.

Numerous themes emerged from Measurement and Evaluation Research panel.

- Collaborations are beneficial to the research community to enhance verification and enable validation of measurement science products.

- Real, operational data is a valuable commodity and its collection and dissemination not only grows the research, but also supports V\&V activities

- Building trust in the manufacturing community is critical to engage in mutually beneficial collaborations

\subsubsection{Industrial AI Systems for Machine PHM}

The final session of the day was a focused presentation entitled "Development of Industrial AI Systems for Machine Prognostics and Health Management," delivered by Dr. Xiaodong 'Alex' Jia. Dr. Jia is an Assistant Professor at the University of Cincinnati and Researcher at the Center for Intelligent Maintenance Systems.

Dr. Jia presented his work in the field of Industrial AI including his specific focus on PHM, analytics, and signal processing. Dr. Jia began his talk by describing AI as a cognitive science that can be applied to numerous fields including image processing and signal processing. The goal of $\mathrm{AI}$ is to mimic human cognition including the aspect of continuous improvement. Dr. Jia highlighted the need for lots of "hands-on" experience with respect to implementing Industrial AI. He cited that physical knowledge can sometimes be counter-intuitive to experience.

Dr. Jia indicated that Industrial AI is built upon the digital twin models and cyber-physical systems (CPS) coming together. Three elements sit below this tier that all must occur in industrial operations - design, manufacturing, and maintenance. He continued to note that four foundational technological areas contribute to these elements: 1) data technology, 2) analytical technology, 3) platform technology, and 4) operational technology. Dr. Jia then simplified the key elements of an Industrial AI system to be people, things, and systems. IoT can allow a single individual to operate multiple systems. Industrial AI connects people to machines through a range of systems. A future-forward direction is to generate a CPS loop (including sensing, analysis, networking, cognition, and decision-making) that will reduce the human burden.

Going into greater detail, Dr. Jia noted that AI tools can address multiple learning problems including detection, clustering, classification, prediction, planning, generalization, and creation. Diving into his PHM research tasks, Dr. Jia spoke on fault detection, fault diagnosis, and fault prognosis. He illustrated these activities in the context of two case studies, the first being with a bandsaw manufacturer. The case study focused on the risks of sawing with degraded blades. If a blade breaks halfway through the cut, then the resultant product will be of poor quality or have to be scrapped, altogether. The research effort featured the implementation of relatively high cost sensors, including accelerometers and acoustic sensors. These sensors were selected because they provide richer data (which also increased the cost of data storage). Low cost sensors were considered for data collection however it was determined that this data was too difficult to process. This study determined that high cost sensors were good for the physical analysis. Lower cost sensors could be beneficial for deep learning.

Dr. Jia's work, and that of the Center for Intelligent Maintenance Systems, highlighted Industrial AI as a systematic discipline that can address industrial problems responsively, repetitively, and reliably.

\section{LESSONS LEARNED}

The ME4PHM Workshop offered many key takeaways and findings. Themes emerged within each panel throughout the day. Some of those themes were consistently present throughout most, if not all, of the panels, whether it was something a speaker presented or a question that was raised by the audience.

- $\quad$ PHM for All Organizations - PHM technologies and capabilities have had benefits and continue to be leveraged by manufacturers of all sizes, from small to large. This fact was highlighted in the first two panels of the day - the large manufacturing panel and the small manufacturing panel. There are some similar challenges across the differing size enterprises (e.g., where to establish a PHM pilot within the enterprise, ensuring enough data is captured to enable PHM). Likewise, enterprises of varying sizes face unique challenges (e.g., larger enterprises typically can afford to spend more money on advancing their maintenance strategies).

- $\quad$ PHM for All Operations - A range of manufacturing operations were discussed throughout the day, each presenting a unique operation of PHM success or use case for PHM consideration. Machine tools, robotics, additive manufacturing, and other automation 
technologies were highlighted. The commonality among these discussions was that the speakers demonstrated that the inclusion of PHM was advantageous to planning and increasing the efficiency of maintenance operations.

- Real Data - Every panel included some level of discussion regarding the availability of real operational data to promote the development, implementation, verification, and validation of PHM capabilities. Real fault and failure data are among the most desired data streams by the community. There is no pure substitute for fault and failure data, especially when it is annotated and organized for analysis. Numerous researchers generate simulated data to support their algorithm development, training, and testing, yet assumptions and uncertainty are always present to a degree in simulation.

- Collaborations - Forming relationships between manufacturers and those that develop and test PHM technologies is vital to advancing the current state-ofthe-art in PHM. Likewise, strong relationships between manufacturers, technology integrators, and researchers can promote more efficient and less costly implementation practices of new PHM capabilities.

- Verification and Validation - The deployment of untested PHM technologies can lead to disaster in a manufacturing environment. Likewise, exhaustively testing a PHM system to detect every potential fault or failure is not practical. Striking the appropriate balance of sufficient V\&V is necessary to build confidence in the PHM system and deploy it for use. Initial deployments should also be viewed as opportunities to gather additional lessons learned and further data sets to add the V\&V knowledge base.

In addition to highlighting the above common threads, the ME4PHM Workshop also illustrated another key point PHM is not only vital to the manufacturing community, it is vital to other key industries including aerospace, automobiles, consumer electronic products, power generation, and transportation. This was evident based upon the diversity of the audience. The audience included personnel from these industries in addition to a strong contingent from the manufacturing community.

The lessons captured during this workshop will influence the next steps identified in the subsequent section to further build up manufacturing PHM technological prowess.

\section{CONClusions AND Future WORK}

This report documented the ME4PHM workshop at the 2019 Annual Conference of the PHM Society. Background from various events leading up to the ME4PHM workshop were

presented and discussed. The ME4PHM panels were summarized and lessons learned were disseminated.

Several next steps are actively occurring or are being planned for future execution. Among the current activities are the efforts of ASME's PHM Subcommittee on Advanced Monitoring, Diagnostics, and Prognostics for Manufacturing Operations $^{3}$ (introduced in Section 3.3). Many of the subcommittee's members attended the ME4PHM Workshop. The knowledge they captured from the workshop is being incorporated into the current development of guidelines to enable manufacturers to determine where and when PHM should be added or augmented in their manufacturing operations. The group is drafting these guidelines to be applicable and serviceable by manufacturers of all sizes, from small to large.

The next ME4PHM Workshop is tentatively planned to occur in May 2022 at NIST's campus in Gaithersburg, Maryland, USA. This event is currently being scheduled for multiple days and is expected to contain keynote presentations and panel discussions (at minimum). Similar to the 2019 ME4PHM Workshop, the goal of this next installment will be aimed at discussing the manufacturing community's PHM priorities and highlighting the growth of PHM technologies and capabilities, including those $\mathrm{V} \& \mathrm{~V}$ products.

This report continues the efforts to bring real industrial and research perspective on the various aspects of developing, deploying, and maintaining PHM solutions. This document, and the workshop that is the foundation for its content, aim to help the PHM community learn from one another and present a path forward for successfully PHM technology integration and use.

\section{ACKNOWLEDGEMENT}

The authors would like to thank Ms. Sara Fuller, Dr. Sarah Lukens, and Dr. Madhusudanan Navinchandran for their support in documenting the discussion throughout the workshop.

\section{NOMENCLATURE}

$A F B$

AI

$A M$

$A P M$

ASME

CAVS

$C B M$
Air Force Base

Artificial Intelligence

Additive Manufacturing

Asset Performance Management

American Society of Mechanical Engineers

Center for Advanced Vehicular Systems

Condition Based Maintenance

${ }^{3}$ https://cstools.asme.org/csconnect/CommitteePages.cfm?Committee $=1023$ $\underline{42234}$ 


\begin{tabular}{|c|c|}
\hline CNC & Computer Numerical Control \\
\hline$C P S$ & Cyber-physical System \\
\hline$D o D$ & Department of Defense \\
\hline$D O F$ & Degree-of-freedom \\
\hline$E R D C$ & $\begin{array}{l}\text { Engineer, Research, and Development } \\
\text { Center }\end{array}$ \\
\hline$F D A$ & Food and Drug Administration \\
\hline$F M E A$ & Failure Modes and Effects Analysis \\
\hline$G E$ & General Electric \\
\hline$I B D O$ & Industrial Big Data Office \\
\hline IIoT & Industrial Internet of Things \\
\hline$I o T$ & Internet of Things \\
\hline$I T$ & Information Technology \\
\hline$I T L$ & Information Technology Laboratory \\
\hline$K P I$ & Key Performance Indicator \\
\hline$M \& E$ & Measurement and Evaluation \\
\hline ME4PHM & $\begin{array}{l}\text { Measurement and Evaluation for } \\
\text { Prognostics and Health Management in } \\
\text { Manufacturing Operations }\end{array}$ \\
\hline$M E P$ & Manufacturing Extension Partnership \\
\hline$M W O s$ & Maintenance Work Orders \\
\hline NIST & $\begin{array}{l}\text { National Institute of Standards and } \\
\text { Technology }\end{array}$ \\
\hline$N S F$ & National Science Foundation \\
\hline OEMs & Original Equipment Manufacturers \\
\hline$O P M$ & Operations Performance Management \\
\hline PHM & Prognostics and Health Management \\
\hline$R \& D$ & Research and Development \\
\hline$R O I$ & Return on Investment \\
\hline SBIR & Small Business Innovation Research \\
\hline$S M E$ & Small to Medium-sized Enterprise \\
\hline$S M M s$ & Small to Medium-sized Manufacturers \\
\hline$T R L$ & Technology Readiness Level \\
\hline$V \& V$ & Verification and Validation \\
\hline
\end{tabular}

\section{NIST DISCLAIMER}

The views and opinions expressed herein do not necessarily state or reflect those of NIST. Certain commercial entities, equipment, or materials may be identified in this document to illustrate a point or concept. Such identification is not intended to imply recommendation or endorsement by NIST, nor is it intended to imply that the entities, materials, or equipment are necessarily the best available for the purpose.

\section{BIOGRAPHIES}

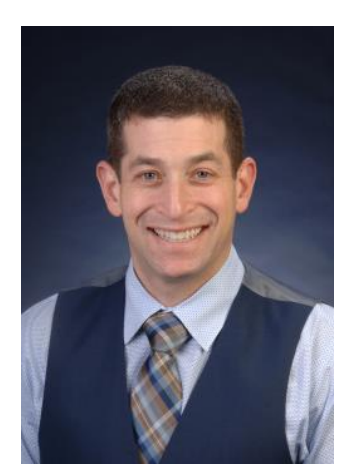

Brian A. Weiss, Ph.D. is a mechanical engineer and the leader of the Prognostics and Health Management for Reliable Operations in Smart Manufacturing (PHM4SM) project within the Engineering Laboratory (EL) at the National Institute of Standards and Technology (NIST). His current research efforts are focused on developing the necessary measurement science to verify and validate emerging monitoring, diagnostic, and prognostic technologies and strategies to enable manufacturers to optimize their planned maintenance and minimize their unplanned maintenance activities. The project is focused on the application domains of machine tools and robot systems. From 2013-2016, Dr. Weiss also served as the Associated Program Manager for the Smart Manufacturing Operations Planning and Control (SMOPAC) program. Prior to his manufacturing research, he spent 15 years conducting performance assessments across numerous military and first response technologies including autonomous unmanned ground vehicles; tactical applications operating on Android $^{\mathrm{TM}}$ devices; advanced soldier sensor technologies; free-form, two-way, speech-to-speech translation devices for tactical use; urban search and rescue robots; and bomb disposal robots. He also spent six years developing robotic crane technologies which included the deployment of a prototype system on a military installation. His efforts have earned him numerous awards including the PHM Society's Contributor of the Year - Individual (2018 \& 2019), a GCN for IT Excellence Award (2014), Department of Commerce Gold Medals (2013 \& 2019), Colleague's Choice Award (2013), Silver Medal (2011), Bronze Medals (2004 \& 2008), and the Jacob Rabinow Applied Research Award (2006). He has a B.S. in Mechanical Engineering (2000), Professional Masters' in Engineering (2003), and Ph.D. in Mechanical Engineering (2012) from the University of Maryland, College Park, Maryland, USA. 


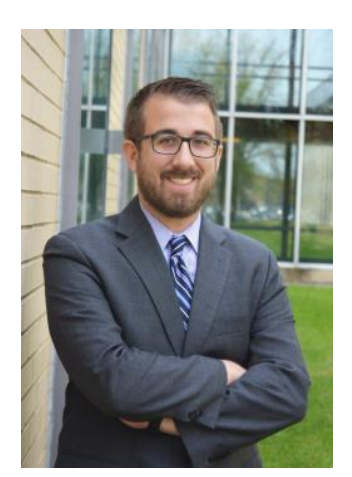

Michael P. Brundage, Ph.D. is an Industrial Engineer in the Informational Modeling and Testing Group at the National Institute of Standards and Technology (NIST). Dr. Brundage leads the Knowledge Extraction and Application for Manufacturing Operations project and is the associate program leader for the Model Based Enterprise program at NIST. Dr. Brundage's interests include Smart Manufacturing Diagnostics for Intelligent Maintenance, Sustainable Manufacturing Performance Measurement, Smart Manufacturing Capability Assessment, and Manufacturing Knowledge Visualization. His work contributes to guidelines for intelligent maintenance and he is the vice chair for the ASME PHM Subcommittee on Monitoring, Diagnostics, and Prognostics for Manufacturing Operations. He also worked closely with ASTM International E60.13 in the development of a guideline for sustainable manufacturing performance indicators (ASTM E3096-17). He authored over 50 peer reviewed publications and has chaired multiple ASME MSEC Symposia and industry forums/workshops at NIST. Dr. Brundage was a 2019-2020 ASME Early Career Leadership Intern Program to Serve Engineering (ECLIPSE) intern and is the recipient of the 2018 ASME Old Guard Early Career Award. Dr. Brundage was selected as one of SME's 2018 Class of 30 Under 30. Prior to joining NIST, Michael attended the University of Notre Dame for his B.S. and Stony Brook University for his M.S. and PhD.

\section{REFERENCES}

Al-Habaibeh, A., \& Gindy, N. (2000). A new approach for systematic design of condition monitoring systems for milling processes. Journal of Materials Processing Technology, 107(1-3), 243-251. doi:Doi 10.1016/S09240136(00)00718-4

Albertelli, P., Goletti, M., \& Monno, M. (2013). A new receptance coupling substructure analysis methodology to improve chatter free cutting conditions prediction. International Journal of Machine Tools and Manufacture, 72, 16-24. doi:https://doi.org/10.1016/j.ijmachtools.2013.05.003

Barajas, L. G., \& Srinivasa, N. (2008). Real-time diagnostics, prognostics health management for large-scale manufacturing maintenance systems. Paper presented at the ASME International Manufacturing Science and Engineering Conference, MSEC2008, Evanston, IL, United States.

Bi, Z. M., Lang, S. Y. T., Shen, W., \& Wang, L. (2008). Reconfigurable manufacturing systems: the state of the art. International Journal of Production Research, 46(4), 967-992. doi:10.1080/00207540600905646
Brundage, M. P., Sexton, T., Hodkiewicz, M., Morris, K. C., Arinez, J., Ameri, F., . . Xiao, G. (2019). Where do we start? Guidance for technology implementation in maintenance management for manufacturing. Journal of Manufacturing Science and Engineering, 141(9).

Coleman, C., Damodaran, S., Chandramouli, M., \& Deuel, E. (2017). Making maintenance smarter: Predictive maintenance and the digital supply network. Retrieved from

https://www2.deloitte.com/content/dam/insights/us/artic les/3828_Making-maintenance-smarter/DUP Makingmaintenance-smarter.pdf

Helu, M., \& Hedberg, T. (2015). Enabling Smart Manufacturing Research and Development using a Product Lifecycle Test Bed. 43rd North American Manufacturing Research Conference, NAMRC 43, 1, 8697. doi:10.1016/j.promfg.2015.09.066

Helu, M., \& Weiss, B. A. (2016). The current state of sensing, health management, and control for small-to-mediumsized manufacturers. Paper presented at the ASME 2016 Manufacturing Science and Engineering Conference, MSEC2016.

Holland, S. (2020). Unsettled Technology Opportunities for Vehicle Health Management and the Role for HealthReady Components.

Holland, S. W., Barajas, L. G., Salman, M., \& Zhang, Y. (2010). PHM for Automotive Manufacturing \& Vehicle Applications. Paper presented at the Prognostics \& Health Management Conference, Portland, Oregon.

International Organization for Standardization. (2009). ISO 18435-1:2009 - Industrial automation systems and integration - Diagnostics, capability assessment and maintenance applications integration - Part 1: Overview and general requirements. In.

International Organization for Standardization. (2012). ISO 13379-1:2012 - Condition monitoring and diagnostics of machines - Data interpretation and diagnostics techniques - Part 1: General guidelines. In.

Jin, X., Siegel, D., Weiss, B. A., Gamel, E., Wang, W., Lee, J., \& Ni, J. (2016). The present status and future growth of maintenance in US manufacturing: results from a pilot survey. Manuf Rev (Les Ulis), 3, 10. doi:10.1051/mfreview/2016005

Jin, X., Weiss, B. A., Siegel, D., \& Lee, J. (2016). Present Status and Future Growth of Advanced Maintenance Technology and Strategy in US Manufacturing. Int J Progn Health Manag, 7(Spec Iss on Smart Manufacturing PHM), 012. Retrieved from https://www.ncbi.nlm.nih.gov/pubmed/28058173

Jovane, F., Koren, Y., \& Boer, C. R. (2003). Present and future of flexible automation: Towards new paradigms. CIRP Annals-Manufacturing Technology, 52(2), 543560. doi:Doi 10.1016/S0007-8506(07)60203-0

Kagermann, H., Helbig, J., Hellinger, A., \& Wahlster, W. (2013). Recommendations for implementing the strategic initiative INDUSTRIE 4.0: Securing the future 
of German manufacturing industry; final report of the Industrie 4.0 Working Group: Forschungsunion.

Kalgren, P. W., Byington, C. S., Roemer, M. J., \& Watson, M. J. (2007). Defining PHM, a lexical evolution of maintenance and logistics. Paper presented at the 2006 IEEE AUTOTESTCON - IEEE Systems Readiness Technology Conference, Anaheim, CA, United states.

Klinger, A., \& Weiss, B. A. (2018). Examining Workcell Kinematic Chains to Identify Sources of Positioning Degradation. Paper presented at the Annual Conference of the PHM Society, Philadelphia, Pennsylvania.

Klinger, A. S., \& Weiss, B. A. (2018). Robotic Work Cell Test Bed to Support Measurement Science for PHM. Paper presented at the 2018 ASME Manufacturing Science and Engineering Conference (MSEC), College Station, Texas.

Kolberg, D., \& Zuhlke, D. (2015). Lean Automation enabled by Industry 4.0 Technologies. Ifac Papersonline, 48(3), 1870-1875. doi:10.1016/j.ifacol.2015.06.359

Lee, J., Lapira, E., Bagheri, B., \& Kao, H.-a. (2013). Recent advances and trends in predictive manufacturing systems in big data environment. Manufacturing Letters, 1(1), 38-41.

Li, Y., Zhao, W. H., Lan, S. H., Ni, J., Wu, W. W., \& Lu, B. H. (2015). A review on spindle thermal error compensation in machine tools. International Journal of Machine Tools \& Manufacture, 95, 20-38. doi:10.1016/j.ijmachtools.2015.04.008

Luxhoj, J. T., Riis, J. O., \& Thorsteinsson, U. (1997). Trends and perspectives in industrial maintenance management. Journal of Manufacturing Systems, 16(6), 437-453. doi:Doi 10.1016/S0278-6125(97)81701-3

Ly, C., Tom, K., Byington, C. S., Patrick, R., \& Vachtsevanos, G. J. (2009). Fault diagnosis and failure prognosis for engineering systems: A global perspective. Paper presented at the 2009 IEEE International Conference on Automation Science and Engineering, CASE 2009, Bangalore, India.

Mori, M., Fujishima, M., Komatsu, M., Zhao, B., \& Liu, Y. (2008). Development of remote monitoring and maintenance system for machine tools. CIRP AnnalsManufacturing Technology, 57(1), 433-436. doi:10.1016/j.cirp.2008.03.108

Pellegrino, J., Justiniano, M., Raghunathan, A., \& Weiss, B. A. (2016). Measurement Science Roadmap for Prognostics and Health Management for Smart Manufacturing Systems. NIST Advanced Manufacturing Seriess (AMS). Retrieved from https://dx.doi.org/10.6028/NIST.AMS.100-2

Peng, Y., Dong, M., \& Zuo, M. J. (2010). Current status of machine prognostics in condition-based maintenance: a review. International Journal of Advanced Manufacturing Technology, 50(1-4), 297-313. doi:10.1007/s00170-009-2482-0

Qiao, G. (2019). Advanced Sensor and Target Development to Support Robot Accuracy Degradation Assessment.
Paper presented at the 2019 IEEE 15th International Conference on Automation Science and Engineering (CASE).

Qiao, G., \& Weiss, B. A. (2017). Accuracy Degradation Analysis for Industrial Robot Systems. Paper presented at the ASME International Manufacturing Science and Engineering Conference, Los Angeles, California.

Qiao, G., \& Weiss, B. A. (2018). Monitoring, diagnostics, and prognostics for robot tool center accuracy degradation. Paper presented at the ASME 2018 13th International Manufacturing Science and Engineering Conference.

Roemer, M. J., Nwadiogbu, E., \& Bloor, G. (2001). Development of diagnostic and prognostic technologies for aerospace health management applications. Paper presented at the 2001 IEEE Aerospace Conference.

Sexton, T., Brundage, M. P., Hoffman, M., \& Morris, K. C. (2017). Hybrid datafication of maintenance logs from aiassisted human tags. Paper presented at the 2017 ieee international conference on big data (big data).

Sexton, T., Hodkiewicz, M., Brundage, M. P., \& Smoker, T. (2018). Benchmarking for keyword extraction methodologies in maintenance work orders. Paper presented at the Proceedings of the Annual Conference of the PHM Society.

Sexton, T. B., \& Brundage, M. P. (2019). Nestor: A Tool for Natural Language Annotation of Short Texts. Retrieved from

Sharp, M., Brundage, M. P., Sprock, T., \& Weiss, B. A. (2019). Selecting Optimal Data for Creating Informed Maintenance Decisions in a Manufacturing Environment. Paper presented at the Model-Based Enterprise Summit 2019.

Sharp, M. E., Sexton, T. B., \& Brundage, M. P. (2016). SemiAutonomous Labeling of Unstructured Maintenance Log Data for Diagnostic Root Cause Analysis.

Szipka, K., Archenti, A., Vogl, G. W., \& Donmez, M. A. (2019). Identification of machine tool squareness errors via inertial measurements. CIRP Annals, 68(1), 547-550. doi:https://doi.org/10.1016/j.cirp.2019.04.070

Thomas, D. S. (2018). The costs and benefits of advanced maintenance in manufacturing: US Department of Commerce, National Institute of Standards and Technology.

Thomas, D. S., \& Weiss, B. A. (2020). Economics of Manufacturing Machinery Maintenance: A Survey and Analysis of US Costs and Benefits.

Vogl, G. W., Calamari, M., Ye, S., \& Donmez, M. A. (2016). A Sensor-Based Method for Diagnostics of Geometric Performance of Machine Tool Linear Axes. Paper presented at the 44th North American Manufacturing Research Conference (NAMRC), Blacksburg, VA.

Vogl, G. W., Galfond, B. C., \& Jameson, N. J. (2019). Bearing Metrics for Health Monitoring of Machine Tool Linear Axes. Paper presented at the 2019 Manufacturing 
Science and Engineering Conference (MSEC 2019), Erie, PA.

Vogl, G. W., Jameson, N. J., Archenti, A., Szipka, K., \& Donmez, M. A. (2019). Root - cause analysis of wear induced error motion changes of machine tool linear axes. International Journal of Machine Tools and Manufacture, $\quad 143, \quad 38-48$. doi:https://doi.org/10.1016/j.ijmachtools.2019.05.004

Vogl, G. W., Weiss, B. A., \& Donmez, M. A. (2014). Standards Related to Prognostics and Health Management (PHM) for Manufacturing (NISTIR 8012). Retrieved from Gaithersburg, Maryland, USA: http://dx.doi.org/10.6028/NIST.IR.8012

Vogl, G. W., Weiss, B. A., \& Helu, M. (2019). A review of diagnostic and prognostic capabilities and best practices for manufacturing. Journal of Intelligent Manufacturing, 30(1), 79-95. doi:10.1007/s10845-016-1228-8

Weiss, B. A. (2019). Developing Measurement Science to Verify and Validate the Identification of Robot Workcell Degradation. Paper presented at the ASME 2019 14th International Manufacturing Science and Engineering Conference (MSEC2019), Erie, Pennsylvania.

Weiss, B. A., Alonzo, D., \& Weinman, S. D. (2017). Summary Report on a Workshop on Advanced Monitoring, Diagnostics, and Prognostics for Manufacturing Operations. Retrieved from

Weiss, B. A., Brundage, M. P., \& Pellegrino, J. (2020). Summary Report: Meeting of the ASME Standards Subcommittee on Advanced Monitoring, Diagnostics, and Prognostics for Manufacturing Operations Hosted at NIST.

Weiss, B. A., Brundage, M. P., Tamm, Y., Makila, T., \& Pellegrino, J. (2019). Summary Report on the Industry Forum for Monitoring, Diagnostics, and Prognostics for Manufacturing Operations. Retrieved from

Weiss, B. A., \& Klinger, A. S. (2017). Identification of Industrial Robot Arm Work Cell Use Cases and a Test Bed to Promote Monitoring, Diagnostic, and Prognostic Technologies. Paper presented at the 2017 Annual Conference of the Prognostics and Health Management (PHM) Society, St. Petersburg, FL.

Weiss, B. A., Vogl, G. W., Helu, M., Qiao, G., Pellegrino, J., Justiniano, M., \& Raghunathan, A. (2015). Measurement Science for Prognostics and Health Management for Smart Manufacturing Systems: Key Findings from a Roadmapping Workshop. Paper presented at the Annual Conference of the Prognostics and Health Management Society 2015, Coronado, CA.

Yamada, A., \& Takata, S. (2002). Reliability improvement of industrial robots by optimizing operation plans based on deterioration evaluation. CIRP Annals-Manufacturing Technology, 51(1), 319-322. doi:Doi 10.1016/S00078506(07)61526-1 